\title{
TEACHERS' COOPERATION WITH PARENTS OF STUDENTS WITH SPECIAL EDUCATIONAL NEEDS
}

\author{
Irena Kaffemanienè \\ Vilnius University Šiauliai Academy, Lithuania \\ Laima Tomėnienè \\ Vilnius University Šiauliai Academy, Lithuania \\ Fausta Verpečinskienė \\ Vilnius University Šiauliai Academy, Lithuania
}

\begin{abstract}
Teachers' cooperation with parents of students with special educational needs (SEN) is particularly important for students with special educational needs. Theoretical analysis has found that there are often problems of cooperation between teachers and parents of children with special educational needs. In order to clarify this, a quantitative study was carried out. The research aim - to reveal the peculiarities of cooperation between teachers and parents of students with special educational needs. The method of a questionnaire survey was chosen for the research, a questionnaire of semi-closed questions was created. The study involved 353 general education teachers. The results of the teacher survey showed that parents are not sufficiently involved in the process of cooperation. The most common forms of cooperation between teachers are individual consultations. The majority of the teachers indicated that they usually cooperate with parents of students with SEN in solving teaching/learning problems of the child, less often they cooperate in developing an individual curriculum. According to the respondents, the main problems are different understanding of responsibilities and demands of teachers and parents on each other.
\end{abstract}

Keywords: cooperation, special educational needs, teachers' and parents' cooperation.

\section{Introduction}

The relevance and problem of the research. The family and the school are the two most important and main institutions of the child's education, the common goal of which is the child's well-being. The UNESCO (2020) Global Education Monitoring Report emphasizes cooperation between teachers and parents raising children with special educational needs (SEN); states that parents need to know all the information, the child's achievements, the challenges faced at school and participate in decision-making.

Hallahan et al. (2014) emphasize that parents can provide teachers with invaluable information about the peculiarities of communication and education of their child with SEN, his/her characteristics and interests. Mitchell (2014) 
states that parents play a very important role in the education of students with SEN, they are sources of information and have rights and responsibilities to participate in the educational process. It is important that teachers and educational support professionals build friendly communication and cooperation relationships with students' parents, share experiences and ideas to help children together, to make the decisions on education correspond to the child's needs (Ćwirynkało \& Bartnikowska, 2020).

Thus, in the opinion of many authors, successful education of the child is inconceivable without the cooperation of the student's family and teachers, however, often in the process of cooperation there are challenges for both teachers and students' parents. According to Dahl (2017), not only for parents but also for teachers, the goals and structure of cooperation are often unclear, their expectations and responsibilities are not defined.

Although the importance of cooperation between teachers and parents raising children with SEN is unquestionable, there is still a lack of empirical evidence about the problems of cooperation between teachers and parents, their causes, and the factors of successful cooperation.

This study analyses problem questions: What are the problems that emerge in the cooperation between teachers and parents of students with SEN? What factors, in the opinion of teachers, determine successful cooperation?

The research aim - to reveal the peculiarities of the cooperation between teachers and parents of students with special educational needs.

Research methods - analysis of scientific literature, method of quantitative research - questionnaire survey, descriptive statistical (percentage frequency) data analysis.

\section{Theoretical Context on Communication and Cooperation of Teachers and Parents}

The scientific literature (Hallahan et al., 2014; Bednarska, 2014; Mitchell, 2014; Rodrigues, Campos, Chaves, \& Martins, 2015, etc.) indicates that cooperation is a joint activity in which forces are united for a common goal. According to Berčnik, Devjak (2017), the partnership between parents, teachers and the educational institution encourages to pursue the common goals together - to provide children with quality education, to constantly share information about the child and his/her achievements, to cooperate in a team based on the principles of mutual assistance and trust (Wasserman, Zwebner, 2017). Thanks to the cooperation between the school and the parents, the child's educational results and the priorities of the whole educational institution are improving (Berčnik, Devjak, 2017). 
However, the researches by Slušnienè, Parišauskienè (2018) and others showed that the development of an educational partnership requires a lot of time and effort. According to Hallahan et al. (2014), families with children with SEN are very vulnerable and constantly under great stress, therefore, teachers need to know not only the peculiarities of the education of a student with SEN, but also his/her parents' attitude to the child's educational opportunities, recognize the experience of the family, take into account the expectations of the family. The results of the research by Rodrigues et al. (2015) showed that teachers, during the cooperation with students' parents, need to discuss with them the goals of child support, educational strategies, find solutions for the organization of education that are acceptable to all the participants in education. The family must become an equal partner in the education of children with SEN. According to Mitchell (2014), in order to build a successful cooperative relationship, it is important to organize periodic meetings, set clear goals for cooperation, shared responsibility for decisions, their results, solve problems, create an atmosphere of cooperation based on mutual respect and trust, review progress in cooperation agreements.

Cooperation between teachers and parents allows teachers to look at the student's situation through the eyes of parents, and parents, cooperating with teachers, better understand their role, help students overcome difficulties, failures, various problems they face every day (Azad, Marcus, Sheridan, Mandell, 2018).

The analysis of scientific sources revealed that both parties - teachers and parents - should promote mutual cooperation, nevertheless, teachers should be the initiators of cooperation. It is important to choose the right forms of cooperation for parents and teachers. They are quite diverse, but it is important that the chosen forms of cooperation are beneficial to the learner, that cooperation is based on mutual trust. The analysis of the scientific literature revealed that in the process of cooperation between teachers and parents, problems often arise, which are overcome by sharing responsibilities and learning from each other; this creates better opportunities to meet the child's special educational needs.

\section{The Methodology of the Research}

Data collection procedure. A method of quantitative research - a questionnaire survey - was chosen for the study. Referring to the analysis of the scientific literature, a semi-closed questionnaire for school teachers educating students with special educational needs was prepared. Multiple-choice questions were prepared for the respondents; it was also possible to express one's opinion by entering the answer ("other"). The questionnaire consists of 19 closed-ended 
Kaffemaniene et al., 2021. Teachers' Cooperation with Parents of Students with Special Educational Needs

and 5 open-ended questions, of four blocks of questions in total: 1 demographic data of respondents; 2 - questions aimed at revealing the opinion of teachers about cooperation with parents of students with SEN, ways of involving parents in cooperation, the roles of teachers and parents in the process of educating children, meeting special educational needs and mutual cooperation; 3 - questions aimed at identifying the applied and most acceptable forms of cooperation between parents and teachers, areas of cooperation and revealing the problems that arise when teachers cooperate with parents raising children with special educational needs; 4 - questions examining teachers' views on the factors of the success of cooperation and the possibility of improving cooperation with parents of students with special educational needs.

The anonymous questionnaire was submitted electronically on the portal www.apklausa.lt. The respondents were explained the purpose of the survey, the anonymity and confidentiality of data were ensured; they were informed of the right to decide whether or not they agree to participate in the anonymous survey. Only persons with a link to the questionnaire sent by the researchers had access to this questionnaire. Invitations to participate in the survey were sent to the teachers of the educational institutions personally by e-mail or the school administration placed a link to the questionnaire in the electronic diaries of the schools.

Methods of data analysis. The research data were processed by SPSS-17 software, applying the methods of descriptive statistics. When processing the answers to the questions about forms of cooperation with parents acceptable to teachers (ranking scale; 1 - "unacceptable”, 2 - "partially acceptable”, 3 "acceptable"); areas of cooperation and factors of successful cooperation (ranking scales; 1 - "not important”; 2 -“less important”, 3 - "important”), Principal Component Analysis, Rotation Method: Oblimin with Kaiser Normalization - KMO was conducted, in accordance with Measure of Sampling Adequacy for Factor Analysis (MSA>0,7). The results of the factor data analysis are presented in tables indicating the data of KMO, test reliability (Cronbach $\alpha$ ), statistical significance (p); factor loading (L) of indicators and factor dispersion (percent).

In order to determine the relationship between the frequency of teachers' meetings with parents of students and the different levels of students' SEN, Crosstabs/Chi-Square Test was applied: Pearson $\chi^{2}, d f$ and statistical significance p (Asymp. Sig.(2-sided) criteria, under the condition that the indicators are statistically dependent when $\mathrm{p}<0,05$; the indicators are statistically independent when $\mathrm{p} \geq 0,05$.

The data of the remaining answers to the questionnaire were calculated in percentage frequencies. The results of the quantitative study are illustrated in tables and figures. 
Study sample. The study involved teachers $(\mathrm{N}=353$, of which 327 women and 26 men), educating students with SEN of primary grades (108); grades 5-10 (172), grades 11-12 (73) in general education schools. Respondents were selected by random non-probability sampling. Most of the respondents have many years of pedagogical experience, they have been working in schools for more than 20 years (60\%); $11-20$ years (23.8\%); only $15 \%$ of the respondents have a length of service of 5 to 10 years.

\section{The Results of the Research}

In the opinion of the absolute majority (98.4\%) of the respondents, the cooperation of teachers with parents of students with SEN is very important.

The opinion of teachers about the benefits of cooperation between teachers and parents was asked. The results of the survey showed that most of the respondents indicated two reasons why cooperation is beneficial: cooperation between teachers and parents creates better opportunities to meet the child's special educational needs (42.2\%) and ensures comprehensive development of the student and the level of learning achievements (39.2\%). A small share of the respondents (10.3\%) indicate that teachers, cooperating with parents of students with SEN, can get to know the student better; positive relationships between the teacher and parents are established (5.3\%); parents' self-esteem improves, there is a greater desire to create a more learning-friendly environment (3\%)

According to the survey data, $89 \%$ of the respondents think that both parties - teachers and parents - should initiate cooperation. Only a small part (7.9\%) of the respondents state that the teacher should be the initiator of cooperation; that parents should take the initiative in the cooperation process (2.5\%); and $0.6 \%$ did not answer the question. According to Berčnik, Devjak (2017), Musiel (2014) and other authors, although parents may be the initiators of dialogue and cooperation, teachers are the ones who have the main responsibility for cooperation with students' parents.

The study aimed to reveal the opinion of teachers about the equivalence of parents of students with SEN in the process of cooperation. The respondents could express their views by entering their answers. The attitude of the majority of the respondents (60.3\%) towards the parents of students with SEN as cooperation partners is positive, however, a third (37.4\%) of the respondents still tend to disagree with the statement that parents are equal partners, underestimate parents' competencies: parents have no special knowledge; are unable to assess the situation realistically and only hinder work; always blame the teacher; parents do not acknowledge, deny, hide that their child has SEN. A very small share of the respondents (2.3\%) indicated that parents raising children with SEN are no different from other parents. 4 respondents did not disclose their opinion. 
Kaffemaniene et al., 2021. Teachers' Cooperation with Parents of Students with Special Educational Needs

The scientific literature indicates that active interaction between teachers and parents, periodic meetings, constant communication are important in the cooperation process. Therefore, the aim was to determine how often teachers meet with parents to discuss the issues of students' education, whether the frequency of meetings depends on the different levels of students' SEN. Figure 1 presents the data on the frequency of meetings of the teachers, who participated in the study, with students' parents according to the level of students' SEN.

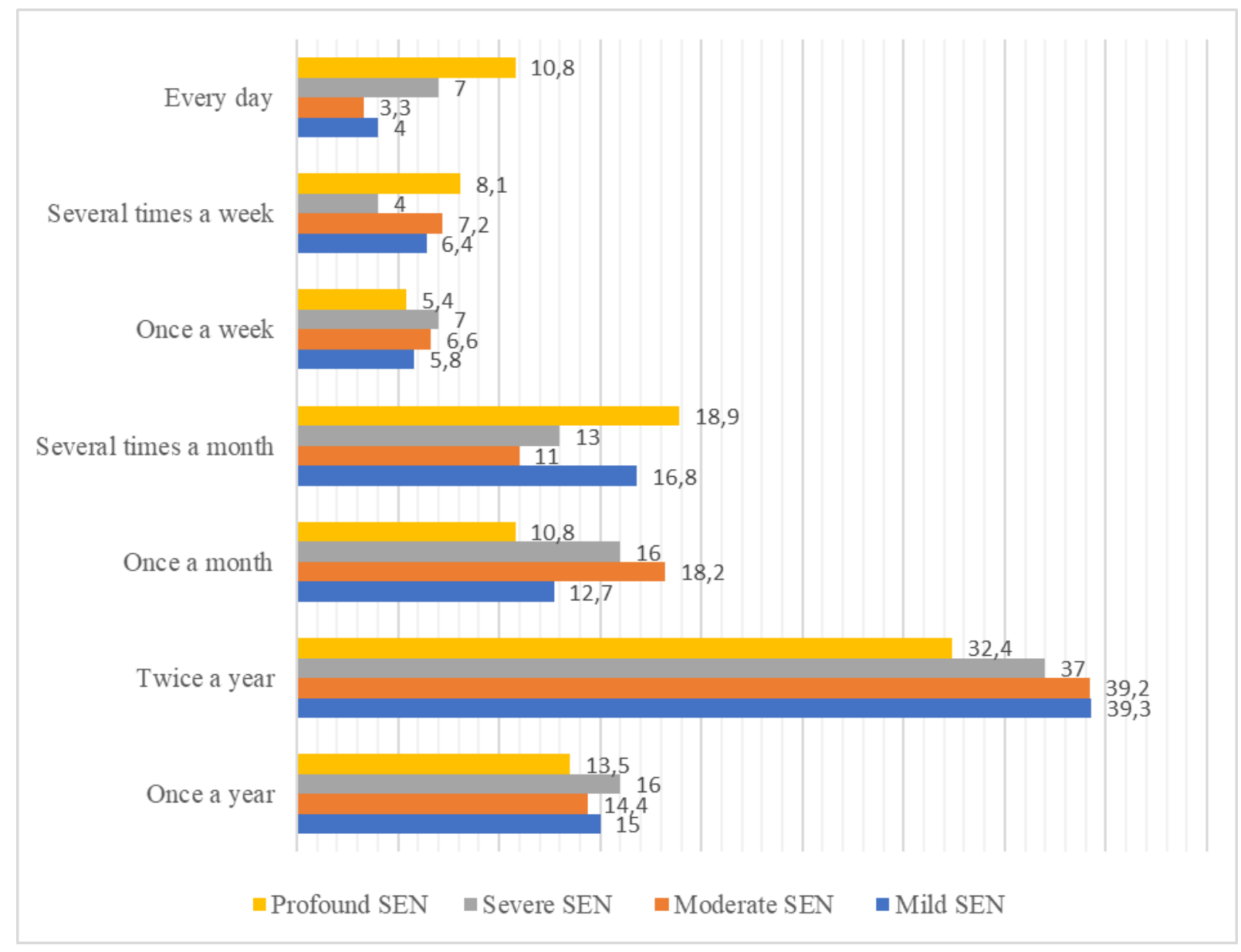

Figure 1 Frequency of Teachers' Meetings with Students' Parents Depending on the Student's SEN, \%

Most of the teachers, who participated in the study, meet with parents of students with different levels of SEN twice a year. Almost one-fifth of the teachers discuss the education of students with different levels of SEN with their parents once or several times a month; about $15 \%$ - once a year. The lowest share of the teachers discusses the education of students with different levels of SEN with parents of students at least once (5-6\%) or several times a week (4-8\%). 
It was found that the frequency of teachers' meetings with parents of students is statistically significantly related to students with mild SEN (Pearson $\left.x^{2}=14,5 ; \mathrm{df}=6 ; \mathrm{p}=0,024\right)$ and moderate SEN (Pearson $x^{2}=13,2 ; \mathrm{df}=6 ; \mathrm{p}=0,040$ ). The frequency of teachers' meetings with parents of students with severe $\left(x^{2}=4,35 ; \mathrm{df}=6 ; \mathrm{p}=0,629\right)$ and profound SEN $\left(x^{2}=4,6 ; \mathrm{df}=6 ; \mathrm{p}=0,601\right)$ is related to the level of students' SEN, however, statistically these dependency relationships are weak.

23.8\% of the teachers commented on their answers about the frequency of meetings with students' parents. According to them, meetings with students' parents take place only in case of need, when problems arise; others indicated that meetings take place 4 times a year, once in 3-4 years, they stated that parents are not interested, do not visit school, do not attend meetings; also emphasized that it all depends on the attitude of the parents and that teachers cannot force them; meetings take place irregularly; very rarely, or do not take place at all. The study revealed that teachers communicate with students' parents infrequently and irregularly. The results show that teachers are still reluctant to cooperate with parents of students with SEN, teachers do not consider parents of students as equal partners.

The research aimed to examine the opinions of teachers about the roles of parents in the process of cooperation with teachers. It was found that the parents of students mostly have the roles of the listener, i.e., listening to and following the instructions of teachers but not proposing to change anything (42.8\%), and the observer (26.6\%), seeing problems but not proposing to change anything either. Only a small share of the respondents (10.8\%) state that parents are active members of the team. The respondents could express their opinion by writing a response option; $10.5 \%$ of such responses were received. According to the teachers, the role of the parents depends on their character: some parents are more observers and listeners, while others are versatile (observers, listeners, initiators, and active team members). $7.6 \%$ of the respondents admit that parents are initiators of cooperation, have specific suggestions, tend to discuss openly.

The respondents were asked how they involve parents of students with SEN in the process of cooperation. Two ways of involving parents in the educational process have emerged: advising parents on how to help their children, what activities to do, and so on (38.2\%) and clearly informing parents about their activities, curricula, goals, progress, etc. (36.8\%). Only a small share of the teachers try to involve parents in cooperation in making decisions (13.6\%).

The scientific literature emphasizes the importance of the diversity of forms of cooperation acceptable for teachers and parents (Dahl, 2017, etc.). It was asked what forms of cooperation are the most acceptable for the teachers who participated in the study. The respondents marked the most acceptable 
Kaffemaniene et al., 2021. Teachers' Cooperation with Parents of Students with Special Educational Needs

forms of cooperation by ranking (acceptable, partially acceptable, unacceptable). The data of the factor analysis of the teachers' responses are presented in Table 1.

Table 1 Forms of Cooperation $(\mathrm{KMO}=0.870 ; p=0.000 ; a=0.869)$

\begin{tabular}{|l|c|c|}
\hline \multicolumn{1}{|c|}{ Structure Matrix } & L & \% \\
\hline \multicolumn{1}{|c|}{ Forms of active cooperation } & & 28.9 \\
\hline Subject-related games & 0.757 & \\
\hline Developing projects together with parents & 0.755 & \\
\hline Question-and-answer evenings & 0.747 & \\
\hline Educational sessions & 0.734 & \\
\hline Disputes, forums & 0.710 & \\
\hline Round table discussions & 0.708 & \\
\hline Conferences & 0.675 & \\
\hline Daily conversation & 0.556 & \\
\hline Joint events for parents and children & 0.547 & \\
\hline \multicolumn{1}{|c|}{ Forms of cooperation based on passive communication } & & 8.1 \\
\hline Correspondence & 0.673 & \\
\hline Communication via class e-diary & 0.612 & \\
\hline Telephone conversations & 0.585 & \\
\hline Parents' meetings & 0.563 & \\
\hline Bulletin boards & 0.558 & \\
\hline Social networks (Facebook), etc. & 0.537 & \\
\hline
\end{tabular}

Two main forms of cooperation have been distinguished by the method of factor analysis of teachers' responses: active cooperation (28.9\%) and cooperation based on passive communication (8.1\%).

The factor Forms of active cooperation consists of variables describing various activities of teachers together with parents of students (subject-related games, L=0.757; project activities, $\mathrm{L}=0.757$; question-and-answer evenings, $\mathrm{L}=0.747$; educational sessions, $\mathrm{L}=0.734$, etc.). Such activities are usually based on non-personalized communication.

Variables of the factor Cooperation based on passive communication correspondence $(\mathrm{L}=0.673)$, communication via class e-diary $(\mathrm{L}=0.612)$, telephone conversations ( $\mathrm{L}=0.585)$, correspondence on social networks $(\mathrm{L}=0.537)$. Although these are individual ways of communicating with parents, they do not require direct contact, are instantaneous and short-term. If communication is defined as the sharing of emotions, thoughts, knowledge, news, and skills (Karaca, 2016), it is reasonably questionable whether parents of 
students with SEN have sufficient communication through correspondence, whether it meets parents' expectations.

The results of the study by Slušnienè, Parišauskienè (2018) are similar. The authors found that the most commonly used forms of individual cooperation are: telephone conversation, online chat, e-mail correspondence, online communication.

Individual respondents $(\mathrm{N}=6)$ commented that they communicate equally with all parents, do not distinguish parents of children with SEN from parents of the whole class, therefore, they do not apply any exceptional forms of cooperation with parents of students with SEN.

The research aimed to find out in which areas of activity teachers and parents of students with special educational needs cooperate. The data of the factor analysis of the answers are presented in Table 2.

Table 2 Areas of Cooperation $(\mathrm{KMO}=0.643 ; \mathrm{p}=0.000 ; \mathrm{a}=0.568)$

\begin{tabular}{|l|c|c|}
\hline \multicolumn{1}{|c|}{ Structure Matrix } & L & \% \\
\hline \multicolumn{1}{|c|}{ Cooperation in organizing education } & 22.9 \\
\hline Preparing an individual education plan, adapted/individual programmes & 0.642 & \\
\hline Assessing the child's special educational needs & 0.576 & \\
\hline Making teaching aids & 0.562 & \\
\hline Organizing parents' meetings & 0.539 & \\
\hline \multicolumn{1}{|c|}{ Cooperation in solving educational problems } & 0.749 & \\
\hline Solving upbringing problems & 0.648 & \\
\hline Solving teaching problems & 0.620 & \\
\hline Discussing doing homework & & \\
\hline
\end{tabular}

Two areas of cooperation with parents of students with SEN have been distinguished by the method of factor analysis: cooperation in organizing education (22.9\%) and cooperation in solving educational problems (13.5\%). Both the variables of the first factor Cooperation in organizing education cooperation in preparing an individual education plan, adapted/individual programmes $(\mathrm{L}=0.642)$, assessing the child's special educational needs $(\mathrm{L}=0.576)$, etc., and the variables of the second factor Cooperation in solving educational problems reflect the typical activities of teachers in educating students with SEN. However, the variables of the second factor show that the problems of students' education are the latent factor of teachers' cooperation with parents.

The process of cooperation is complex, therefore, there are often problems between both parties (parents and teachers). The study aimed to identify the main problems of cooperation between teachers and parents from the point of 
Kaffemaniene et al., 2021. Teachers' Cooperation with Parents of Students with Special Educational Needs

view of teachers. The research data revealed three main problems: parents' reluctance to take responsibility for their children's education (33.4\% of the teachers' responses); different understanding of responsibility for the child's future (17\% of the responses) and uncoordinated demands of teachers and parents on each other (15.9\% of the responses). Barriers to cooperation related to the school are described as the inability to communicate, to choose alternative cooperation strategies. Problems related to parents are described as cultural differences between families, pragmatic worries, psychological barriers, such as negative experiences of cooperation with the school, and so on (Ozmen, Akuzum, Zincirli, Selcuk, 2016). The answers of the teachers who participated in the research show that, in their opinion, the problems of cooperation are mostly related to the unwillingness or inability of students' parents to cooperate, their insufficient competencies. Similar data are shown by Musiel's (2014) study, which found that teachers underestimate parents' competencies. On the other hand, referring to Ozmen et al. (2016), it can be stated that the reasons for the lack of cooperation may be related to the teachers' own lack of interest in cooperation - in principle, this is evidenced by many data from the present study.

$5.4 \%$ of the teachers who participated in the study do not see any problems with cooperation with parents of students with SEN at all. Some respondents expressed their own opinion by entering their own answer (4.8\%). According to them, it would be possible to mark all the answers about the cooperation problems provided in the questionnaire. The respondents state that the main problem is that the child has severe special educational needs, the parents do not recognize that their child needs help.

Referring to Mitchell (2014), the questionnaire included statements that we presented to the respondents to examine their views on the factors of successful cooperation. The data of the factor analysis of the responses are presented in Table 3.

According to Ozmen et al. (2016), effective communication improves students' achievement and provides support to parents, students, teachers, and schools. The factor analysis of the responses identified two key factors of successful cooperation: mutual help and responsibility in pursuing common educational goals (45.9\%) and mutual learning, continuous self-analysis and mutual respect (9.9\%). In the structure of the first factor, the variables related to the functionality of cooperation are most strongly expressed - mutual assistance without condemning and judging each other $(\mathrm{L}=0.803)$; joint agreements $(\mathrm{L}=0.754)$; joint responsibility for problem solving and results $(\mathrm{L}=0.737)$. 
SOCIETY. INTEGRATION. EDUCATION

Proceedings of the International Scientific Conference. Volume III, May $28^{\text {th }}-29^{\text {th }}$, 2021. 51-64

Table 3 Factors of Successful Cooperation $(K M O=0.884 ; p=0.000 ; a=0.856)$

\begin{tabular}{|l|c|c|}
\hline \multicolumn{1}{|c|}{ Structure Matrix } & L & $\%$ \\
\hline \multicolumn{1}{|c|}{ Mutual help and responsibility in pursuing common educational goals } & 45.9 \\
\hline Mutual assistance without condemning and judging each other & 0.803 & \\
\hline Joint agreements & 0.754 & \\
\hline Joint responsibility for problem solving and results & 0.737 & \\
\hline Clear goals of cooperation & 0.683 & \\
\hline Mutual respect for ideas and suggestions & 0.682 & \\
\hline \multicolumn{1}{|c|}{ Mutual learning, continuous self-analysis and mutual respect } & 9.9 \\
\hline Readiness to learn from each other & 0.831 & \\
\hline Periodic meetings and review of achieved goals & 0.720 & \\
\hline Anticipation of possible conflicts and their solutions & 0.710 & \\
\hline Atmosphere of mutual respect and trust & 0.626 & \\
\hline
\end{tabular}

As Ozmen et al. (2016) state, trust-based communication between teachers and parents is very important in identifying problems, looking for ways to solve them, providing learning support to students. The variables of the second factor - mutual learning, continuous self-analysis and mutual respect - reveal the importance of the value-based aspects of successful cooperation based on mutual respect. The variable readiness to learn from each other $(\mathrm{L}=0.831)$ indicates the aspect of trust in each other's competencies; periodic meetings and review of achieved goals ( $\mathrm{L}=0.720$ ) reveals the importance of continuous cooperation and self-analysis; the variable anticipation of possible conflicts and their solutions $(\mathrm{L}=0.710)$ shows that it is important for the participants in cooperation to agree not only on how to work, but also to anticipate behaviour in complicated situations in order to achieve harmonious cooperation (the variable - atmosphere of mutual respect and trust, $\mathrm{L}=0.626$ ).

The research data revealed that all the factors that Mitchell (2014) singled out as important in the cooperation of parents and teachers are also very important for our respondents.

Nevertheless, the research data revealed that a large share of the teachers who participated in the study (58.9\%) are not satisfied with the cooperation with parents of students with SEN, because, according to them: parents do not express a willingness to cooperate; have no desire to take care of their children, parents are hardly interested in their children, they do not help them at home; there is a lack of parents' contribution to learning, etc. Some teachers tend to delegate the cooperation with students' parents to educational support professionals, claiming that the teacher does not have time for that, special educators, psychologists have to do it. Consequently, the research revealed that teachers are not interested in cooperating with parents raising children with 
Kaffemaniene et al., 2021. Teachers' Cooperation with Parents of Students with Special Educational Needs

SEN: I do not want to cooperate with some of them myself. According to Ozmen et al., (2016), communication between teachers and parents is not always possible due to many barriers of different levels: both due to school resources, lack of professionalism of teachers, and due to the peculiarities of the student's family.

Only a quarter of the respondents (24.4\%) are satisfied with the current cooperation with parents of students with SEN. According to them, parents are benevolent; willing to cooperate, they are supportive and willing to help their children. Some of them state that we achieve the desired results only through joint efforts. Thus, it can be said that the cooperation of some teachers with parents is smooth.

$13.6 \%$ of the respondents indicate that they are partially satisfied with cooperation. They state that: it would be good to have the greater involvement of parents in joint events for students and their parents, educational activities; they point out that cooperation is fragmented; parents lack initiative, there is a lack of parents' activity in discussing their expectations. 3.1\% of the respondents did not write their opinion on this issue.

\section{Conclusions}

The research data revealed that teachers recognize the importance of cooperation with parents of students with special educational needs, however, many of them are reluctant to cooperate with students' parents, meetings with students' parents are infrequent and irregular.

It has been found that in some cases, the frequency of meetings with parents of students depends on the level of students' SEN. A statistically significant relationship was found between the frequency of meetings with parents of students with mild and moderate SEN. A weak statistical relationship was found analysing the frequency of meetings with parents of students with severe and profound SEN.

The most important areas of teachers' cooperation with students' parents were found to be cooperation in organizing education (preparing an individual education plan, adapted/individual programmes, assessing the child's special educational needs, etc.) and cooperation in solving educational problems. According to the data of the factor analysis, the problems of students' education are the latent factor of teachers' cooperation with students' parents.

The role of parents in the process of cooperation with teachers is unequal. According to the teachers who participated in the research, parents are mostly passive listeners and observers. However, often teachers do not seek closer cooperation either: they only inform parents about the child's achievements, 
perhaps that is why students' parents are poorly involved in making decisions about the child's education.

According to the teachers, the main barriers to cooperation are parents' reluctance to take responsibility for their children's education; different understanding of teachers' and parents' responsibility for the child's education, uncoordinated demands of teachers and parents on each other. The study revealed that a large number of teachers tend to underestimate parents' competencies and do not consider them as equal partners. Teachers tend to blame parents of students.

\section{References}

Azad, G.F., Marcus, S.C., Sheridan, S.M., \& Mandell, D.S. (2018). Partners in school: An innovative parent-teacher consultation model for children with autism spectrum disorder. Journal of Education and Psychological Consultation, 28(4), 460-486. doi: https://doi.org/10.1080/10474412.2018.1431550

Bednarska, M. (2014). School-house relationships on different stages of children and teenagers (youth) development. Pedagogy, 114(2), 106-115.

Berčnik, S., Devjak, T. (2017). Cooperation between parents and preschool institutions through different concepts of preschool education. Center for Educational Policy Studies Journal, 7(4), 207-226.

Ćwirynkało, K., Bartnikowska, U. (2020). The opinions of foster parents on the personal level of cooperation with teachers in the context of children's special educational needs. A scientific report. Interdisciplinary Contexts of Special Pedagogy, 29, 75-95. Poznań: Adam Mickiewicz University.

Dahl, K.K.B. (2017). Too much parental cooperation? Parent-teacher cooperation and how it influences professional responsibility among Danish schoolteachers. Power and Education, 9(3), 177-191.

Hallahan, D.P., Kauffman, J.M., \& Pullen, P.C. (2014). Exceptional learners: An introduction to special education (12th ed.). United States of America: Pearson Education Limited.

Karaca, M. (2016). Communication from sociological perspective. Electronic Journal of Social Sciences, 15(57), 626-648.

Mitchell, D. (2014). What really works in Special and Inclusive Education: using evidence based strategies. New York: Routledge.

Musiel, E. (2014). Teacher-parent cooperation and pupils' achievements in the perception of adult respondents (based on the example of secondary schools). Pedagogy, 114(2), 96-105.

Ozmen, F., Akuzum, C., Zincirli, M., Selcuk, G. (2016). The communication barriers between teachers and parents in primary schools. Eurasian Journal of Educational Research, 66, 26-46. DOI: http://dx.doi.org/10.14689/ejer.2016.66.2

Rodrigues, F.B., Campos, S., Chaves, C., Martins, C. (2015). Family-school cooperation in the context of inclusion of children with special educational needs. Procedia - Social and Behavioral Sciences, 171, 309-316.

Slušnienè, G., Parišauskienè, D. (2018). Possibilities of information technology usage collaborating with parents of schoolchildren. Role of Higher Education Institutions in Society: Challenges, Tendencies and Perspectives, 1(7), 180-186. 
Kaffemaniene et al., 2021. Teachers'Cooperation with Parents of Students with Special Educational Needs

UNESCO. (2020). Inclusion and education: all means all. Global education monitoring report. Paris: UNESCO.

Wasserman, E., Zwebner, Y. (2017). Communication between Teachers and Parents using the WhatsApp Application. International Journal of Learning, Teaching and Educational Research, Vol.16, 12, 1-12. 